\title{
REKONSTRUKSI CERITA MAHABHARATA DALAM DAKWAH WALISONGO
}

\author{
Adisti Candra Nariswari \\ Fakultas Dakwah dan Komunikasi UIN Walisongo \\ Email:adisticn@gmail.com \\ Nur Cahyo Hendro Wibowo \\ Fakultas Dakwah dan Komunikasi UIN Walisongo \\ Email:nur_cahyo@walisongo.com
}

\begin{abstract}
7 The emergence of stories which had Islamic nuances in the puppet, known as Walisongo's creation. Walisongo with the intelligence to read the situation and conditions of society at that time, adopt and remodel stories in the puppet by inserting the teachings of Islam. One of the stories in the puppet is Mahabharata.Those changes used by Walisongo as media of dakwah, so that becomes the problem in this research is how the development of Mahabharata story after Walisongo. The research had the purposes to know the development of Mahabharata story after Walisongo use it to propagate of Islam in Java, which has been inserted the teachings of Islam.

This study is a qualitative research that focuses on the study of literature (library research) about the books Mahabharata, the Javanese culture (puppet), Walisongo, and dakwah. As well as data analysis in this research using descriptive analysis, an attempt to describe and analyze the development of Mahabharata after Walisongo and the continuer use it in the context of the spread of Islam in Java.

The results showed that the development of Mahabharata story after Walisongo include: first, the Pandavas symbolized as pillars of Islam, in order to facilitate the public in the first time in knowing and understanding the five pillars of Islam. Second, the story polyandry character Draupadi in Mahabharata Hindu had changed by Walisongo into monoandri, because Islam prohibits women married to more than one males (polyandry). Third, the Heroine figure in the Hindu Mahabharata was transsexual then turned into a real woman, because in Islam are not allowed to violate their nature, are men who resemble women and women who resemble men. Fourth, the priest Drona good
\end{abstract}


role models and wisely changed to a negative figure, interpreted as the views lowly clergy who abide the king. Fifth, Punakawan figure which is the native Java and then interpreted as a demonstration Walisongo or da'i. Sixth, comes pedigree Hindu god be the descendants of Prophet Adam to eliminate idolatry. Seventh, the emergence of new stories bouquet of the trustees containing the teachings of Islam, such as the story Dewaruci, amulets Kalimasada, mustaka Weni, and Petruk Dadi Ratu.

Key words: Mahabharata, dakwah, Walisongo.

\begin{abstract}
ABSTRAKSI
$\mathrm{M}$ unculnya kisah-kisah dalam pewayangan yang bernuansa Islam diketahui merupakan karya Walisongo. Walisongo dengan kepandaian membaca situasi dan kondisi masyarakat waktu itu, mengadopsi dan merombak cerita-cerita dalam pewayangan dengan menyisipkan ajaran-ajaran Islam di dalamnya. Salah satu cerita dalam pewayangan yaitu cerita Mahabharata. Perubahan-perubahan tersebut merupakan pemanfaatan media dakwah oleh Walisongo, sehingga yang menjadi rumusan masalah dalam penelitian ini adalah bagaimanakah pengembangan cerita Mahabharata setelah adanya Walisongo. Tujuan yang hendak dicapai dalam penelitian ini adalah untuk mengetahui pengembangan cerita Mahabharata setelah digunakan Walisongo dalam rangka penyebaran ajaran Islam di Jawa yang telah disisipkan ajaran Islam.
\end{abstract}

Penelitian ini merupakan penelitian kualitatif yang memfokuskan diri pada studi kepustakaan (library research) mengenai buku-buku Mahabharata, budaya Jawa (pewayangan), Walisongo, dan dakwah. Penelitian ini analisis data menggunakan analisis deskriptif, sebagai upaya untuk menguraikan dan menganalisis pengembangan cerita Mahabharata setelah digunakan Walisongo dan penerusnya dalam rangka penyebaran ajaran Islam di Jawa.

Hasil penelitian menunjukkan bahwa pengembangan cerita Mahabharata setelah adanya Walisongo meliputi: pertama, Pandawa disimbolkan sebagai rukun Islam, agar memudahkan masyarakat pada waktu dulu dalam mengetahui dan memahami lima pilar agama Islam. Kedua, cerita poliandri tokoh Drupadi dalam cerita Mahabharata Hindu dirubah Walisongo menjadi monoandri, karena Islam melarang wanita menikah dengan lebih dari satu laki-laki (poliandri). Ketiga, tokoh Srikandi yang dalam Mahabharata Hindu merupakan waria kemudian berubah menjadi perempuan sejati, karena Islam tidak memperbolehkan menyalahi kodratnya, yaitu pria yang menyerupai perempuan dan perempuan yang menyerupai pria. Keempat, pendeta Drona tokoh 
panutan yang baik dan bijaksana dirubah menjadi tokoh negatif, dimaknai sebagai pandangan hina rohaniawan yang tunduk kepada raja. Kelima, dimunculkannya tokoh Punakawan yang merupakan asli Jawa kemudian dimaknai sebagai peraga Walisongo atau da'i. Keenam, muncullah silsilah dewa Hindu yang menjadi keturunan dari Nabi Adam untuk menghilangkan kemusyrikan. Ketujuh, munculnya ceritacerita baru karangan para wali yang mengandung ajaran-ajaran Islam, seperti cerita Dewaruci, Jimat Kalimasada, Mustaka Weni, dan Petruk Dadi Ratu.

Kata Kunci: Mahabharata, Dakwah, Walisongo.

\section{PENDAHULUAN}

MANUSIA merupakan makhluk sosio-budaya yang memperoleh perilakunya lewat belajar yang pada umumnya dipengaruhi oleh kekuatan-kekuatan sosial dan budaya. Budaya dan komunikasi tidak dapat dipisahkan, karena budaya tidak hanya menentukan siapa, tentang apa, dan bagaimana orang menyandi pesan, tetapi makna yang dimiliki untuk pesan, dan kondisi-kondisinya untuk mengirim, memperhatikan dan menafsirkan pesan tersebut (Mulyana, 2014: 19).

Dari semua aspek belajar manusia,komunikasimerupakanaspek yang terpenting dan paling mendasar. Komunikasi merupakan alat utama untuk memanfaatkan berbagai sumber daya lingkungan dalam pelayanan kemanusiaan. Melalui komunikasi, manusia dapat menyesuaikan diri dan berhubungan dengan lingkungannya (Mulyana, 2014: 137). Salah satunya dengan komunikasi massa, yaitu suatu proses komunikasi sosial yang dilakukan individu-individu untuk berinteraksi dengan lingkungan sosio- budayanya, tanpa terlihat dalam hubungan-hubungan antarpersona dengan individu-individu tertentu (Mulyana, 2014: 142). Dakwah merupakan salah satu bentuk kegiatan komunikasi. Sehingga dakwah yang dilakukan Walisongo merupakan kegiatan komunikasi yang melibatkan interaksi dengan lingkungan sosiobudaya.

Walisongo mengenalkan Islam kepada penduduk lokal dalam bentuk kompromi dengan kepercayaankepercayaan lokal yang mapan yang banyak diwarnai takhayul atau kepercayaan-kepercayaan animistik lainnya (Azra, 2002: 20-21). Salah satunya dengan mengembangkan kebudayaan. Dakwah Walisongo tersebut biasa disebut dengan dakwah kultural, yaitu dakwah yang mendekati objek dakwah (mad'u) dengan memperhatikan aspek sosial budaya yang berlaku di masyarakat (Saputra, 2011:3).

Dalam proses berdakwah yang dilakukan oleh sebagian para wali, wayang bukan dihapus tapi justru digunakan semaksimal mungkin 
menjadi alat pendukung dalam menyebarkan agama Islam. Bagi masyarakat Jawa, wayang tidak sekedar sarana hiburan, tetapi juga sebagai media pendidikan bahkan media dakwah. Walisongo yang sering memanfaatkan pertunjukan wayang sebagai media pengenalan Islam kepada penduduk adalah Sunan Bonang dan Sunan Kalijaga. Sunan Bonang dan Sunan Kalijaga berdakwah dengan menjadi dalang dalam sebuah pertunjukkan wayang.

\section{Adanya kisah-kisah hasil} olahan yang bersumber pada cerita Mahabharata menjadi menarik untuk penulis teliti. Penelitian ini menjadi penting mengingat belakangan ini ada sebagian pihak yang meragukan eksistensi Walisongo dalam dunia dakwah Nusantara. Lebih parahnya ada sebagian pihak yang menganggap keberadaan Walisongo hanya sebatas mitos. Seperti dalam Ensiklopedia Islam terbitan Ikhtiar Baru Van Hoeve, Walisongo dan usaha-usaha dakwahnya tidak dicantumkan. Tidak hanya karya tersebut yang menganggap Walisongo adalah fakta ahistoris, dalam buku Walisanga Tak Pernah Ada? karya Sjamsudduha juga menganggap Walisongo tidak pernah ada, dan lain sebagainya (Agus Sunyoto, 2014: vi). Hal ini bisa mengaburkanperandakwahWalisongo zaman dulu dalam menyisipkan ajaran Islam. Maka penelitian ini menjadi penting guna menggali fakta-fakta sejarah khususnya tentang peran yang nyata dilakukan Walisongo dalam berdakwah, seperti dengan menanamkan nilai keislaman di tanah air (khususnya pulau Jawa) dengan media wayang.

Berdasarkan latar belakang yang telah dipaparkan, maka permasalahan yang ingin penulis angkat adalah bagaimanakah perkembangan cerita Mahabharata setelah adanya Walisongo. Tujuan yang hendak dicapai dalam penelitian ini adalah untuk mengetahui pengembangan cerita Mahabharata setelah digunakan Walisongo dalam rangka penyebaran ajaran Islam di Jawa yang telah disisipkan ajaran Islam.

Walisongo merupakan suatu lembaga dakwah Islam yang beranggotakan delapan orang wali, dan digantikan secara periodik bila ada anggota yang meninggal atau kembali ke negeri asalnya (Chodjim, 2013: 11-12). Sehingga dapat disimpulkan Walisongo berarti perkumpulan para wali yang terhimpun dalam suatu lembaga dakwah sekitar abad ke-15 dan ke-16. Tidak mengherankan jika nama para wali yang terhimpun dalam Walisongo antara satu daerah bisa berbeda dengan daerah lain.

Pementasan wayang sebelum Walisongo, alur cerita yang baku diambil dari kisah-kisah dalam epos Mahabharata dan Ramayana yang merupakan bagian dari kitab suci Hindhu. Kisah-kisah yang banyak digemari masyarakat Jawa kuno, yang ternyata banyak menyimpang dari ajaran Islam. R. Poedjosoebroto (1978) menyebutkan bahwa unsur-unsur dalam wayang yang tidak dapat diterima oleh ummat pada waktu itu adalah, pertama dari bentuk wayang yang menyerupai manusia, karena berbentuk arca-arca kecil. 


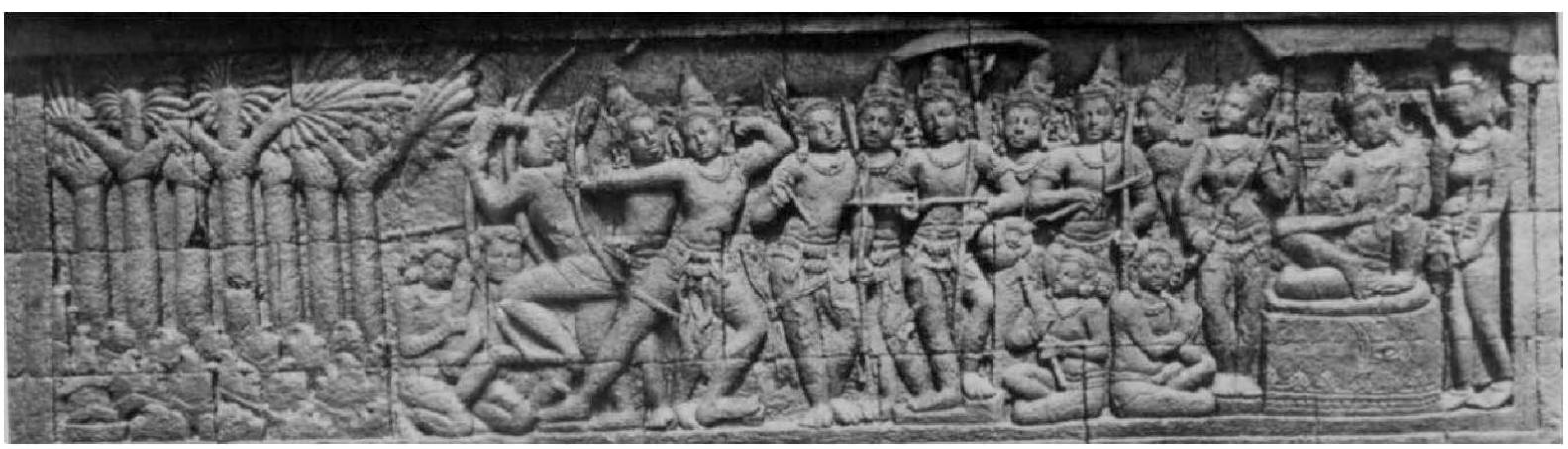

Gambar 3. Arca-Arca Wayang

Gambar-gambar dan patung dalam Islam diharamkan karena menyerupai ciptaan Allah dan menyamai buatanNya. Patung dari makhluk hidup seperti manusia, hewan dan lain-lain hukumnya haram sebagaimana hadits yang diriwayatkan Aisyah ra. : Pernah Rasulullah SAW masuk (ke rumahku) sedang aku dibalik gorden yang bergambar, maka berubahlah rona wajahnya, kemudian tabir itu ditariknya hingga robek seraya bersabda: "Sesungguhnya di antara orang yang paling berat siksaannya pada hari kiamat nanti ialah orang-orang yang (menggambar) menyerupai ciptaan Allah". Aisyah berkata: "Maka kupotonglah kain itu lalu kujadikan dua buah bantal, sedang Nabi SAW senang (menggunakan) bantal-bantal itu'. (HR. Bukhori) (Hamidy, dkk., 2007: 39)

Para wali melihat hikmah dari diharamkannya gambar-gambar dan patung yang tersebut sebelumnya adalah agar menjauhi keberhalaan, memelihara aqidah dari kesyirikan dan penyembahan berhala. Sebab yang membawa umat-umat terdahulu kepada penyembahan berhala, karena adanya gambar-gambar dan patungpatung tersebut (Hamidy, dkk., 2007:
35).

Kedua, cerita-cerita dewa yang membawakemusyrikan. Ceritatentang dewa-dewa Trimurti (Brahma-WisnuSiwa) yang dianggap oleh penganut agama Hindu sebagai "Tuhan" zat yang berkuasa di atas manusia biasa (Zarkazi, 1996: 79). Dewa Syiwa bertugas membinasakan dunia, Wisnu yang bertugas memelihara dunia, serta Brahma yang bertugas menciptakan dunia (Astiyanto, 2006: 348). Terdapat juga dewa-dewa Hindu lain seperti dewa Indra, Bayu, Surya, dan sebagainya. Dewa-dewa tersebut dipuja dan dipercaya oleh masyarakat waktu dulu, karena dewa dianggap sebagai makhluk suci yang berkuasa terhadap alam semesta. Para wali berusaha menggeser kedudukan dewa tersebut untuk menghilangkan kemusyrikan, karena dalam Islam diperintahkan hanya menyembah Allah SWT seperti dalam An-Nahl ayat 36.

Ketiga, cerita-cerita yang positif (yang mengandung ajaran-ajaran kebaikan) tetapi nilai keislamannya tidak ada. Seperti cerita Mahabharata yang pada intinya menceritakan tentang Pandawa (kebaikan) melawan 
Kurawa (keburukan) tetapi pada akhirnya dimenangkan oleh Pandawa, cerita tersebut mempunyai nilai positif tetapi belum terdapat ajaran Islam di dalamnya. Sehingga wali berusaha merombak cerita-cerita pewayangan sebelumnya dengan menyisipkan ajaran Islam di dalamnya.

Walisongo dengan kepandaian membaca situasi dan kondisi masyarakat saat itu, mengadopsi dan merombak cerita-cerita dari epos Mahabharata tersebut dengan menyisipkan ajaran-ajaran Islam di dalamnya. Salah seorang dari Walisongo yang aktif menyadur tokoh-tokoh dari cerita Mahabharata adalah Sunan Kalijaga. Sunan Kalijaga juga menciptakan lakon (cerita) wayang baru dan menyelenggarakan pergelaran-pergelaran wayang. Ceritacerita hasil olahan ini yang kemudian sering dikenal sebagai lakon-lakon carangan (Anasom, dkk., 2004: 40).

Mahabharata merupakan cerita klasik India yang dikenal luas oleh masyarakat Indonesia. Garis besar ceritanya adalah meneladani manusia bahwa kejahatan selalu kalah oleh kebajikan. Tokoh kebajikan diperankan oleh kerabat Pandawa, sedangkan lawannya Kurawa (Depdiknas, 2008: 62). Cerita pokok Mahabharata mengenai peperangan antara Kurawa sebagai keturunan Kuru dengan Pandawa sebagai keturunan Bharata. Kemenangan-kemenangan sementara dari Kurawa merupakan ujian kesabaran bagi Pandawa, yang akhirnya diikuti dengan kemenangan akhir bagi Pandawa yang dapat mendirikan kerajaan yang mulia
(Poedjosoebroto, 1978: 9).

Pada masa Majapahit, raja dan rakyat menyembah dewa Syiwa, oleh karena hal tersebut maka Walisongo terutama Sunan Kalijaga lebih menitikberatkan penampilan kisah Mahabharata daripada Ramayana (Ismunandar, 1985: 98). Sebab cerita Mahabharata merupakan kitab suci bagi pemeluk agama Syiwa, sedangkan kitab Ramayana merupakan salah satu kitab suci bagi pemeluk agama Wisnu (Anasom, dkk., 2004: 18).

\section{METODE PENELITIAN}

Pada penelitian ini maksud rekonstruksi adalah mengungkapkan kembali sebagaimana adanya mengenai perkembangan cerita Mahabharata setelah adanya Walisongo dan diteruskan oleh penerusnya. Perkembangan tersebut meliputi perubahan-perubahan dari cerita Mahabharata yang sudah disisipi ajaran Islam. Cerita Mahabharata yang dimaksud adalah kisahkisah yang dibawakan dalam pewayangan. Mengingat Walisongo dan raja Demak zaman dulu telah mengeluarkan sembilan ketetapan yang tersebut dalam latar belakangdan menjadikannya dasar perubahan dalam pergelaran wayang, maka berdasarkan pada ketetapan tersebut peneliti akan mencari ajaran Islam yang terkandung dalam gubahan cerita Mahabharata tersebut.

\section{Teknik Pengumpulan Data}

Penelitian ini menggunakan riset kepustakaan (library research) 
yang bersifat literer, yakni sumbersumber digali dari bahan-bahan yang terkait dengan topik melalui bukubuku dan bahan-bahan pustaka. Riset kepustakaan atau sering juga disebut studi pustaka, ialah serangkaian kegiatan yang berkenaan dengan metode pengumpulan data pustaka, membaca dan mencatat serta mengolah bahan penelitian (Zed, 2004: 3). Dalam konteks ini penulis menggunakan buku-buku yang berkaitan dengan cerita Mahabharata, budaya Jawa (pewayangan), Walisongo, dan dakwah.

Selain riset kepustakaan juga ditambah dengan cara wawancara. Menurut Sugiyono (2012: 138-140), wawancara dapat dilakukan secara terstruktur dan tidak terstruktur. Pertama wawancara terstruktur adalah metode pengumpulan data dimana peneliti sudah menyiapkan pertanyaan-pertanyaan tertulis yang alternatif jawabannya sudah disiapkan. Kedua wawancara tidak terstruktur merupakan wawancara secara bebas dimana peneliti tidak menggunakan pedoman wawancara yang telah tersusun secara sistematis. Wawancara yang penulis maksud adalah wawancara tidak terstruktur untuk mendapatkan data-data yang penulis munculkan bisa terjawab secara maksimal. Peneliti akan melakukan wawancara kepada narasumber seperti dengan tokoh budayawan dan ahli sejarah Islam Nusantara, Agus Sunyoto (penulis buku Atlas Walisongo), serta wawancara terhadap dalang yang masih aktif melakukan pertunjukan wayang dengan membawakan cerita Mahabharata versi gubahan Walisongo.

\section{Analisis Data}

Analisis data merupakan kegiatan menelaah, mengelompokkan, mensistematisasikan, menafsirkan dan memverifikasi data agar sebuah fenomena memiliki nilai sosial, akademis dan ilmiah. Metode analisis yang digunakan peneliti ialah analisis deskriptif, yaitu usaha untuk mengumpulkan dan menyusun suatu data, kemudian dilakukan analisis terhadap data tersebut (Surakhmad, 1990: 139). Dalam menganalisis data, penulis menggunakan deskriptif analitik sebagai upaya untuk menguraikan dan menganalisis perkembangan cerita Mahabharata setelah digunakan Walisongo dan penerusnya dalam rangka penyebaran ajaran Islam di Jawa yang telah disisipkan ajaran Islam.

\section{TEMUAN HASIL PENELITIAN}

Berikut adalah bagian-bagian dari perkembangan cerita Mahabharata setelah adanya Walisongo serta pujangga Islam Jawa.

\section{Perubahan Tokoh}

\section{a. Pandawa (Pandawa Simbol Rukun Islam)}

Walisongo mempersonifikasikan rukun Islam yang berupa lima perkara dengan tokoh lima Pandawa (R. M. Ismunandar, 1985: 97). Personifikasi tersebut merupakan metode dak- 
wah Sunan Kalijaga bersama murid-muridnya dulu, karena bagi masyarakat Jawa tokoh dan karakter Pandawa dalam pergelaran wayang dijadikan semacam idola atau pribadi yang dikagumi. Pandawa yang terdiri dari lima bersaudara Yudhistira, Bima, Arjuna, Nakula dan Sadewa, mengisyaratkan kepada lima rukun Islam. Dengan disimbolkannya Pandawa dengan rukun Islam bertujuan untuk memudahkan masyarakat pada waktu dulu dalam mengetahui dan memahami lima pilar agama Islam.

Karena bagi masyarakat Jawa tokoh dan karakter Pandawa dalam pergelaran wayang dijadikan semacam idola atau pribadi yang dikagumi. Pandawa yang terdiri dari lima bersaudara Yudhistira, Bima, Arjuna, Nakula dan Sadewa, mengisyaratkan kepada Lima Rukun Islam.

\section{b. Drupadi (Cerita tentang Poliandri)}

Tokoh Drupadi yang merupakan istri dari lima Pandawa dalam Kisah Mahabharata Hindu. Drupadi yang dikisahkan mempunyai lima anak dari masing-masing Pandawa. Anak Drupadi dari urutan suami Pandawa adalah Prativinda, Srutasoma, Srutakarna, Satanika, serta dengan Sadewa anak Drupadi bernama Srutakarman. Kemudian para Wali merubah sosok Drupadi hanya menjadi istri Yudhistira, saudara tertua Pandawa. Hasil perkawinan Drupadi dengan Yudhistira mempunyai satu anak bernama Pancawala.

Perubahan penokohan Drupadi mempunyaialasanyangpenting,bahwa Walisongo ingin memberitahukan bahwa dalam ajaran Islam tidak mengizinkan wanita menikah dengan lebih dari satu laki-laki (poliandri). Al-Qur'an menjelaskan firman Allah SWT mengenai larangan poliandri dalam An-Nisa ayat 24. Jelaslah bahwa perempuan yang bersuami, haram dinikahi oleh laki-laki lain. Ayat tersebut merupakan dalil Al-Qur'an atas haramnya poliandri. Hikmah utama dari larangan poliandri adalah untuk menjaga kemurnian keturunan dan kepastian hukum si anak.

\section{c. Srikandi Perempuan Sejati}

Tokoh Srikandi dalam cerita Mahabharata Hindu adalah anak lakilaki Prabu Drupada yang pada waktu lahir adalah seorang perempuan bernama Sinandini atau Shikkadin. Kemudian setelah bertukar kelamin dengan raksasa Stunakarna. Tetapi kemudian tokoh Sinandini berubah dengan digambarkan sebagai seorang perempuan sempurna dengan nama Srikandi. Srikandi juga dikisahkan sebagai istri Arjuna.

Perubahan penokohan Srikandi seorang waria yang kemudian digambarkan menjadi perempuan sempurna, dimaksudkan karena dalam Islam tidak memperbolehkan menyalahi kodratnya. Bahkan Rasulullah SAW melaknat orang yang memiliki jenis kelamin tertentu kemudian meniru-niru orang yang memiliki jenis kelamin lainnya. Seperti dalam hadits berikut: 
Artinya: Ibnu Abbas ra. Berkata: Rasulullah saw. melaknat laki-laki yang menyerupai perempuan dan perempuan yang bergaya lakilaki. Rasulullah saw. Melaknat lakilaki yang meniru perempuan dan perempuan yang meniru laki-laki (HR. Bukhari) (Nawawi, 2006: 783).

Pria yang menyerupai perempuan dan perempuan yang menyerupai pria merupakan bahaya yang mencemaskan dan dapat mengancam keberadaan umat. Karena seseorang yang berbuat hal tersebut telah keluar dari fitrah dan mengabaikan jenis kelamin. Sesuai fitrahnya bahwa perempuan seharusnya berpakaian, berperilaku, dan bertindak seperti layaknya perempuan.

\section{d. Drona Sosok yang Negatif}

Drona atau Durna digambarkan sebagai tokoh yang sangat dihormati dan merupakan tokoh pendeta sakti yang berjiwa perwira dalam cerita Mahabharata Hindu, kemudian oleh para wali dirubah menjadi pendeta yang memiliki jiwa atau roh jahat. Diceritakan pada saat muda Durna memiliki wajah yang tampan dan tubuh yang ideal, tetapi kemudian Durna dihajar oleh Gandamana sampai seluruh tubuhnya rusak. Akibat Durna takabur dengan kelebihannya, sedangkan sifat tersebut merupakan larangan Allah.

Penggambaran Durna secara negatif tersebut, ditafsirkan sebagai pandangan hina rohaniawan/ ulama yang tunduk kepada raja. Sebab, ketika seorang ulama terlalu tunduk bahkan melampaui batas, maka fungsi ulama sebagai hakim atas para raja bisa jadi hilang dan ulama tersebut bisa dikendalikan oleh raja/ penguasa untuk kepentingan-kepentingan yang negatif. Inilah yang membuat para Walisongo mengubah Durna dijadikan sosok yang negatif karena terlalu patuh kepada raja, meskipun raja tersebut hendak melakukan maksiat. Ajaran Islam mengikuti ke jalan yang buruk tidak ada kewajiban di dalamnya, sebagaimana sabda Rasulullah:

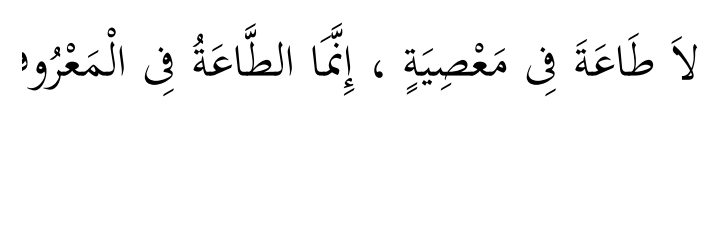

Artinya: "Tidak ada kewajiban ta'at dalam rangka bermaksiat (kepada Allah). Ketaatan hanyalah dalam perkara yang ma'ruf (bukan maksiat)." (HR. Bukhari)

Ulama yang tunduk terhadap penguasa termasuk dalam golongan ulama yang lengah dan lalai. Maksud dari kelalaian ulama adalah seperti lebih memihak kepada kepentingan penguasa daripada kepentingan masyarakat atau kepentingan agama. Pada masa sekarang, karena ulama banyak disegani maka kemudian yang menjadi permasalahan adalah apabila ada oknum-oknum politik yang memanfaatkan para ulama untuk menarik simpati banyak orang. Sehingga dikhawatirkan nantinya ulama-ulama tersebut terkatrol oleh 
penguasa politik yang mempunyai kepentingan-kepentingan negatif.

\section{Penambahan Tokoh Baru (Punakawan)}

Munculnya tokoh baru Punakawan sebagai peraga Walisongo atau para da'i. Punakawan yang terdiri dari Semar, Nala Gareng, Petruk, dan Bagong. Keempat figur wayang yang nama-namanya sama sekali tidak terdapat dalam epos Hindhu Mahabharata sebagai sumber cerita pewayangan aslinya, tetapi merupakan tokoh asli Nusantara. Keempat tokoh tersebut dimunculkan Walisongo dalam cerita Mahabharata untuk memperagakan serta mengabdikan fungsi, watak, tugas konsepsional Walisongo dan pendakwah Islam.

\section{Penambahan Cerita (Silsilah Dewa dengan Islam)}

Para Wali dan penerusnya membangun fondasi Islam yang kokoh terhadap suatu tradisi Hindu, yakni ketuhanan (divinity) dewa Hindu ditolak. Istilah dewa tersebut digunakan untuk tokoh-tokoh wayang, tetapi tidak pernah menjadi istilah pengganti untuk Allah dan istilah-istilah lain yang digunakan untuk Tuhan. Dewa bukan merupakan tuhan-tuhan (gods) sebagaimana yang terdapat dalam mistisisme HinduJawa. Dewa adalah manusia dan dalam hal tersebut merupakan nenek moyang raja-raja Jawa. Transformasi tersebut menghubungkan nabi-nabi Arab dengan dewa-dewa Hindu, dan melalui serangkaian mitos yang kompleks menghubungkan tokoh- tokoh wayang dengan sembilan Wali (Woodward, 1999: 333). Selain Sunan Kalijaga dan wali lainnya, pujangga besar Kraton Surakarta, Raden Ngabehi Ranggawarsita juga banyak berperan dalam menyempurnakan lakon-lakon wayang dakwah. Antara lain dengan memasukkan nama-nama nabi (menurut agama Islam) ke dalam silsilah wayang purwa (Sena Wangi, 2008: 402).

\section{Munculnya Cerita Baru}

Walisongo juga menyusun ceritacerita baru yang bernafaskan Islam seperti Dewaruci, Jimat Kalimasada, Mustoko Weni, dan Petruk Dadi Ratu. Denganjalan ini, maka Islam menyebar di kawasan Nusantara berlangsung secara halus dan damai, tanpa ada keguncangan dan keterkejutan.

\section{a. Dewaruci/Bimasuci}

Kisah Dewaruci menceritakan dan menggambarkan perjalanan Bima mencari kesempurnaan hidup. Bima dengan niat dan laku yang sungguhsungguh, sentosa, kuat, dan teguh pendiriannya serta tidak ragu, dapat menemukan guru sejatinya yaitu Dewa Ruci. (Soeparno, Soesilo, 2007: 48).

Kisah Dewaruci atau Bimasuci sangat populer di kalangan orang Jawa. Cerita tersebut yang diyakini merupakan tulisan salah seorang dari Walisongo, yaitu Sunan Kalijaga. Dalam upaya menyebarkan Islam, para wali menggunakan berbagai macam strategi dakwah, karenanya penulisan cerita Dewaruci dipandang 
sebagai salah satu strategi dakwah tersebut. Serta menjadi simbol dari pengalaman pribadi Sunan Kalijaga ketika beliau memperoleh pelajaran spiritual dengan tokoh gaib, yang diyakini umat Islam sebagai Nabi Khidir a.s..

Sunan Kalijaga menggambarkan Dewaruci sebagai personifikasi dari Nabi Khidir dan Bima adalah dirinya sendiri yang tidak puas dengan nasihat gurunya Sunan Bonang. Artinya bahwa hubungan antara Bima dengan Dewaruci sama halnya antara Sunan Kalijaga dengan Nabi Khidir. Sunan Kalijaga juga diberi pengetahuan mengenai diri manusia, dan tentang asal-usul segala kejadian dan masalah gaib lainnya (Ahimsha-Putra, 2001: 363). Pengalaman Sunan Kalijaga dianggap sebagai pengalaman seorang muslim, maka citra Islam dalam kisah Dewaruci menjadi kental. Sehingga masyarakat Jawa dulu yang gemar dengan cerita pewayangan tersebut, menjadi paham serta memandang dan menafsirkan berbagai ajaran Islam yang terkandung dalam pewayangan (Ahimsha-Putra, 2001: 365). Jadi, dengan adanya simbolisasi perjalanan seorang muslim yang mencari ilmu dalam bentuk kisah pewayangan Dewaruci, maka percampuran antara wayang sebagai unsur budaya dari masa pra-Islam dengan Islam dipandang pantas dan cocok. Sehingga orang Jawa tidak lagi melihat wayang dan Islam sebagai dua hal yang berbeda.

b. Cerita Jimat Kalimasada

Walisongo memodifikasi makna konsep jimat kalimah sada yang asalnya berarti jimat kali maha usada (bernuansa teologi Hindu) menjadi bermakna azimah kalimat syahadah, yang merupakan pernyataan seseorang tentang keyakinan bahwa tiada Tuhan selain Allah dan bahwa Muhammad adalahutusanAllah(Sena Wangi, 2008: 725). Keyakinan tersebut merupakan spirit hidup dan penyelamat kehidupan bagi setiap orang. Dalam perspektif Islam, kalimah syahadat merupakan kunci surga yang mengantarkan manusia menuju keselamatan di dunia dan akhirat. Maksudnya, bahwa hal tersebut mempunyai kekuatan spiritual bagi yang mengucapkannya.

Dalam pewayangan, Walisongo tetap menggunakan hal tersebut untuk mempersonifikasikan senjata ampuh bagi manusia. Jika pada perspektif Hindu, jimat tersebut diwujudkan dalam bentuk benda simbolik berupa tombak pemberian dari dewa, maka Walisongo mendesakralisasi sehingga hanya sebagai pernyataan tentang keyakinan terhadap Allah dan rasul-Nya (Suparjo, 2008: 184). Apabila diperhatikan dengan baik bahwa cerita Jimat Kalimasada merupakan kisah carangan, yakni kisah yang dibuat diluar dari sumber cerita Mahabharata asli (Hindu). Kisah tersebut menceritakan salah satunya mengenai masuknya Prabu Darmokusumo/Yudhistira dalam agama Islam. Adanya cerita tersebut, masyarakat Jawa dapat menafsirkan dan memahami peralihan kebudayaan serta pergantian agama dari HinduBudha ke Islam sebagai sesuatu yang wajar, kemudian memahami bahwa 
budaya Islam adalah budaya yang benar dan pantas diikuti.

Pengarang cerita Jimat Kalimasada menggambarkan kesaktian dan kedasyatan kalimah syahadat. Sehingga ummat Islam diperingatkan oleh pengarang agar tetap menjaga dan cermat terhadap ancaman Dewa Srani (Nasrani). Tokoh Batara Guru yang memberikan Jimat Kalimasada dalam kisah tersebut, dipandang sebagai wakil dari para dewa dan hal ini merupakan restu dari para dewa untuk peralihan agama Prabu Yudhistira. Perpindahan tersebut menjadi terasa semakin sah dan wajar, karena adanya kekuatan Jimat Kalimasada yang dapat membuat Yudhistira hidup lama (Ahimsha-Putra, 2001: 369). Kekuatan ini dapat dimaknai sebagai pernyataan implisit bahwa agama Islam lebih superior daripada agama yang dianut Yudhistira sebelumnya, walaupun dalam pewayangan tidak pernah dinyatakan secara jelas mengenai agama dari tokoh-tokoh wayang.

Kemunculan cerita Jimat Kalimasada telah memahamkan orang Jawa untuk menghubungkan kehidupan masa Hindu-Budha dengan kehidupan masa Islam, serta dimaknai sebagai perpindahan agama dari non-muslim ke agama Islam sebagai sesuatu yang dapat diterima dan perlu diikuti.

\section{c. Mustaka Weni}

Cerita Mustaka Weni memperingatkan kepada umat Islam bahwa apabila memuja-muja nenek moyang seperti yang dilakukan kaum Hindu maka kalimah syahadat/ kesaksian Islamnya hilang. Karena hal tersebut merupakan syirik (Zarkazi, 1996: 83). Diceritakan bahwa Pandawa yang sedang sibuk membangun candi untuk memuja nenek moyangnya kemudian kehilangan pusaka Jimat Kalimasada. Jimat tersebut dicuri oleh Mustakaweni, tetapi kemudian Jimat Kalimasada dapat kembali ke Yudhistira.

Cerita tersebut menggambarkan apabila seseorang mulai menyukutukan Allah, maka keimanan tentang keesaan Allah akan hilang. Pembangunan candi Saptaargo oleh Pandawa dimaknai dengan contoh perbuatan syirik, karena candi tersebut dibangun untuk memuja arwah leluhurnya. Kemudian Jimat Kalimasada yang menjadi simbol kalimat syahadat hilang dicuri Dewi Mustakaweni, hal tersebut dapat diartikan sebagai ketauhidan kepada Allah yang sirna akibat berbuat syirik. Dalam cerita Mustaka Weni terdapat ajaran Islam, seperti dalam Al-Qur'an tentang larangan berbuat syirik atau menyembah sesuatu selain Allah.

\section{d. Petruk Dadi Ratu}

Cerita Petruk Dadi Ratu diyakini diciptakan oleh Sunan Kalijaga. Cerita tersebut di luar dari cerita Mahabharata Hindu, pengarangnya hanya menggunakan tokoh-tokoh yang ada dalam Mahabharata. Petruk Dadi Ratu menceritakan bagi siapa saja yang berpegang teguh pada kalimat syahadat, makan akan berjaya. Digambarkan segala apa yang dikehendaki berkat rahmat 
dan petunjuk Allah akan terlaksana. Demikian Petruk yang menyimpan Jimat Kalimasada, bisa menjadi raja yang tidak terkalahkan.

Cerita Petruk Dadi Ratu dapat diambil kesimpulan bahwa betapapun seseorang hinanya seperti Petruk, apabila dia memegangi Jimat Kalimasada (Islam) maka akan menjadi sakti dan mendapatkan kebahagiaan dunia maupun akhirat.

\section{PENUTUP}

Adanya kenyataan historis tentang keberadaan cerita pewayangan yang menyimpan dari sumber aslinya (Mahabharata Hindu), memperjelas tentang usaha-usaha yang dilakukan Walisongo dalam merombak setting budaya dan tradisi keagamaan yang ada di tengah masyarakat pada waktu dulu. Pada zaman dulu budaya wayang sangat melekat dan tidak terpisahkan bagi masyarakat Jawa, sehingga pemanfaatannya sebagai media dakwah menjadi sangat efektif.

Wayang dalam perjalanannya dari zaman ke zaman telah mengalami berbagai macam perubahan akibat adanya perubahan dalam pemerintahan, politik, sosial budaya dan kepercayaan, sesuai dengan perubahan yang terjadi dalam pikiran manusia serta kemajuan teknologi yang mendorong manusia untuk lebih maju dan kreatif lagi. Dakwah Walisongo justru mengakomodasikan Islam sebagai ajaran agama yang mengalami historisasi dengan kebudayaan. Dengan adanya kisah-kisah seperti Dewaruci, Jimat Kalimasada, dan lain- lain, budaya pewayangan kemudian dipandang sebagai sesuatu yang Jawa dan juga sekaligus Islam. Pemaknaan baru tersebut tidak akan mengubah pakem cerita, tetapi telah mampu membangun nilai-nilai Islam dalam cerita pewayangan.

\section{DAFTAR RUJUKAN}

Ahimsha-Putra, Heddy Shri (2001). Strukturalisme Levi-Strauss: Mitos dan Karya Sastra. Yogyajarta: Galang Press.

Anasom, Musahadi, Mundiri, Asmoro Hadi (2004). Membangun Negara Bermoral: Etika Bernegara dalam Naskah Klasik Jawa-Islam. Semarang: Pustaka Rizki Putra.

Astiyanto, Heniy (2006). Filsafat Jawa: Menggali Butir-Butir Kearifan Lokal. Yogyakarta: Warta Pustaka Yogyakarta.

Azra, Azyumardi (2002). Islam Nusantara: Jaringan Global dan Lokal. Bandung: Penerbit Mizan.

Bahreisy, Salim (1977). Bekal Juru Dakwah. Surabaya: Balai Buku.

Chodjim, Achmad (2013). Sunan Kalijaga: Mistik dan Makrifat. Jakarta: PT. Serambi Ilmu Semesta.

Depdiknas (2008). Ensiklopedi Anak Nasional: Jilid 12. Bogor: PT Delta Pamungkas.

Hamidy, Mua'ammal, Imron A. Manan (2007). Terjemahan Tafsir Ayat Ahkam Ash-Shabuni 3. Cet. VII. Surabaya: PT. Bina Ilmu.

Ismunandar, R. M. (19850. Wayang Asal-Usul dan Jenisnya. 
Semarang: Dahara Prize.

Mulyana, Deddy, \& Jalaluddin Rakhmat (2014). Komunikasi Antarbudaya: Perpaduan Berkomunikasi dengan Orang-orang Berbeda Budaya. Cet. XIV. Bandung: PT. Remaja Rosdakarya.

Nawawi, Imam (2006). Syarah dan Terjemah Riyadhus Shalihin. Jakarta: Al-I'tishom.

Poedjosoebroto, R. (1978). Wayang Lambang Ajaran Islam. Jakarta: PT. Pradnya Paramita.

Saputra, Wahidin (2011). Pengantar Ilmu Dakwah. Jakarta: Rajawali Pers.

Sena Wangi (2008). Ensiklopedi Wayang Indonesia. Jilid I. Jakarta: Sena Wangi.

Simon, Hasanu (2004). Misteri Syekh Siti Jenar: Peran Walisongo dalam Mengislamkan Tanah Jawa. Yogyakarta: Pustaka Pelajar.

Soeparno \& Soesilo (2007). Nilai-Nilai Kearifan Budaya Jawa. Malang: Yayasan Yusula.

Sugiyono (2012). Metode Penelitian Kuantitatif, Kualitatif, dan $R \& D$. Bandung: Alfabeta.

Sunyoto, Agus (2014). Atlas Wali Songo: Buku Pertama yang Mengungkap Wali Songo sebagai Fakta Sejarah. Jakarta: Pustaka Iman.

Suparjo (2008). Islam dan Budaya: Strategi Kultural Walisongo dalam Membangun Masyarakat Muslim Indonesia. Jurnal Komunika, 2, 2, Juli-Desember.

Surakhmad, Winarno (1990).
Pengantar Penelitian Ilmiah: Dasar, Metode, dan Teknik. Bandung: Tarsito.

Woodward, Mark R (2012). Islam Jawa: Kesalehan Normatif versus Kebatinan. Yogyakarta: Lkis.

Zarkazi, Effendy (1996). UnsurUnsur Islam dalam Pewayangan; Telaah atas Penghargaan Wali Sanga terhadap Wayang untuk Media Dakwah: Cet II. Jakarta: PT. Margi Wahyu.

Zed, Mestika (2004). Metode Penelitian Kepustakaan. Jakarta: Yayasan Obor Indonesia. 